\title{
NEUTRONICS DESIGN ASPECTS OF REFERENCE ARIES-I FUSION BLANKET
}

\author{
by \\ E.T. CHENG*and the ARIES DESIGN TEAM
}

This is a preprint of a paper to be presented at the Ninth Topical Meeting on the Technology of Fusion Energy, October 7-11, 1990, in Oak Brook, Illinois and to be printed in the Proceedings.

Work supported by

U.S. Department of Energy

Contract DE-AC03-89ER52153

*TSI Research, Solana Beach, California.

GENERAL ATOMICS PROJECT 3469

DECEMBER 1990

\section{GEMERAL ATOMIICS MASTER




\title{
NEUTRONICS DESIGN ASPECTS OF REFERENCE ARIES-I FUSION BLANKET
}

\author{
E.T. CHENG* and the ARIES DESIGN TEAM
}

General Atomics, P.O. Box 85608, San Diego, California 92186-9784.

-Present address: TSI Research, 225 Stevens Ave., Suite 110, Solana Beach, California 92075.

\section{ABSTRACT}

A SiC composite blanket concept was recently conceived for a deuterium-tritium burning, $1000 \mathrm{MW}(\mathrm{e})$ tokamak fusion reactor design, ARIES-I. SiC composite structural material was chosen due to its very low activation features. High blanket nuclear performance and thermal efficiency, adequate tritium breeding, and a low level of activation are important design requirements for the ARIES-I reactor. The major approaches, other than using $\mathrm{SiC}$ as structural material, in meeting these design requirements, are to employ beryllium, the only low activation neutron multiplying material, and isotopically tailored $\mathrm{Li}_{2} \mathrm{ZrO}_{3}$, a tritium breeding material stable at high temperature, as blanket materials.

\section{INTRODUCTION}

ARIES- $I$ is a deuterium-tritium (D-T) burning, $1000 \mathrm{MW}(\mathrm{e})$ tokamak fusion reactor based on advanced technology and modest extrapolation from the present physics data base. ${ }^{1,2} \mathrm{SiC}$ composite material was selected as the structural material for ARIES-I blanket and shield due to its very low activation features. Beryllium metal was determined to be the neutron muitiplier becnuse of the high $(n, 2 n)$ performance capability and low activation aspect. The low activation motivations for the ARIES-I design were primarily relevant to safety and environmental issues of nuclear energy. The considerations were extended to the following areas: (1) accidental release of radioactive inventory; (2) maintenance and decommissioning; and (3) waste disposal and reuse of materials.

A previous design of the ARIES-I blanket selected $\mathrm{Li}_{4} \mathrm{SiO}_{4}$ as the tritium breeding material because of its very low activation characteristics. ${ }^{3}$ However, due to the concern that a phase change from $\mathrm{Li}_{4} \mathrm{SiO}_{4}$ to $\mathrm{Li}_{2} \mathrm{SiO}_{3}$ during neutron irradiation may impose potential difficulties in operating the blanket at desired temperatures, the reference breeding material was changed to $\mathrm{Li}_{2} \mathrm{ZrO}_{3}$, which is a more stable material at high temperatures diring lithium burnup transmutation. ${ }^{4}$ Due to afterheat and radiation hazard considerations, the natural zirconium element in the breeder, $\mathrm{Li}_{2} \mathrm{ZrO}_{3}$, is tailused to consist of enriched $\mathrm{Zr}$-92 isotope $(0.057 \% \mathrm{Zr}-90,0.013 \%$ $\mathrm{Zr}-91,99.91 \% \mathrm{Zr}-92,0.019 \% \mathrm{Zr}-94$, and $0.003 \% \mathrm{Zr}-96)$ in its isotopic abundance.

In this paper, we discuss the neutronics design aspects of the reference ARIES-I blanket based on the new breeding material, $\mathrm{Li}_{2} \mathrm{ZrO}_{3}$. The safety aspects of this blanket due to induced radioactivity are discussed in Ref. 5.

\section{ARIES-I BLANKET CONCEPT}

High blanket nucless performance is one of the design requirements for the ARIES-I reactor. The major approarh in meeting this design requirement is to employ beryllium, the only low activation neutron multiplying material, as the blanket material. Lead is the other possible non-fissionable neutron multiplier. However, the radiological hazard potential for lead in a fusion reactor is at least four orders of magnitude higher than $\mathrm{SiC}$ and beryllium.

In the conceptual design of the ARIES-I blanket, we are motivated to minimize the beryllium inventory due to resource limitation concerns. The best approach to effectively utilize the beryllium neutron multiplication is to install the beryllium component immediately behind the first wall and to maximize the beryllium fraction in this zone. To enhance the nuclear energy multiplication in the ARIES-I blanket, we allow the excess neutrons to be absorbed in silicon $(Q=8.5 \mathrm{MeV})$ which appears in the beryllium zone as the constituent element in the structural material, $\mathrm{SiC}$.

Due to the coolant routing and heat-removal design approach adopted for the ARIES--I blanket, a minimal power density design is required in the breeder zone such that the maximum operating temperature in the breeder would not exceed the design limit. To fulfill this important design requirement, we have arranged the location of the breeder material to be as close to the 
first wall as possible. Another neutronics consideration for having the breeding material just behind the first wall is to enhance tritium breeding by reducing parasitic absorption.

Due to the above discussed requirements, we have selected the blanket concept that employs a beryllium neutron multiplyi:.1g zone immediately behind the first wall. The tritium breeder, which is a solid breeding material, is uniformly mixed with beryllium to reduce the operating power density. High lithium- 6 enrichment in the solid breeding compound will be needed due to high lithium-6 burnup in the blanket. Table 1 shows the zoning and material compositions of the ARIES-I blanket and shield design.

As shown in Table 1, the blanket consists of a structural first wall made of $\mathrm{SiC}$ composite. The neutronic model used in the calculation assumes a thickness of $1 \mathrm{~cm}$ for the first structural wall with the compositions of $67 \% \mathrm{SiC}$ and $33 \%$ helium, by volume. In front of the first structural wall, there is a sacrificial layer of $2 \mathrm{~mm}$, also made of $\mathrm{SiC}$, to account for the particle erosion due to plasma edge interactions. The breeding zone is located immediately behind the first wall. It consists of $25 \% \mathrm{SiC}, 70 \%$ breeder and multiplier, and $5 \%$ helium, also by volume. The breeder and multiplier is comprised of $80 \%$ beryllium and $20 \%$ solid breeder material. Both beryllium and solid breeder are at $90 \%$ of their respective theoretical density. The packing fraction of the breeder and multiplier in this zone is $80 \%$ using twosize particles. The breeder and multiplier zone is $0.2 \mathrm{~m}$ thick and is backed by two reflector zones. Figure 1 displays the tritium breeding ratio (TBR), blanket energy multiplication $(\mathrm{M})$, and ${ }^{8} \mathrm{Be}(\mathrm{n}, 2 \mathrm{n})$ reaction rate as a function of breeder/multiplier zone thickness. The $0.2 \mathrm{~m}$ breeder/multiplier zone thickness was chosen based on the considerations of adequate breeding (1.2 in 1-D calculation) and minimum beryllium inventory.

The front reflector zone is $0.1 \mathrm{~m}$ thick consising of $25 \% \mathrm{SiC}, 70 \%$ beryllium, and $5 \%$ helium. Use of beryllium in this reflecting zone is primarily to enhance the blanket energy multiplication by about $3 \%$. The rear reflecting zone is made of $25 \% \mathrm{SiC}$ (structure), $70 \% \mathrm{SiC}$ (particles), and $5 \%$ helium. The thickness of this SiC reflector zone is $0.07 \mathrm{~m}$ in the inboard location, otherwise it is $0.37 \mathrm{~m}$. Note the non-structural material in the reflector zones, either beryllium or $\mathrm{SiC}$, is $90 \%$ dense and is with $80 \%$ packing fraction using two-size particles. Figure 2 displays $M$ and $T B R$ as a function of packing fraction of the $\mathrm{Li}_{2} \mathrm{ZrO}_{3} / \mathrm{Be}$ particles in the ARIES-I blanket. Note that the corresponding TBR will change by about $7 \%$ when the packing fraction of these breeder/muitiplier particles in ARIES-I varies by $10 \%$, as shown in Fig. 2. The blanket energy multiplication, however, is to be affected by only about $2 \%$.

The $\mathrm{SiC}$ reflector zone is thein followed by a $0.3 \mathrm{~m}$ gas plenum with the compositions of $75 \% \mathrm{SiC}$ and $25 \%$

Table 1. Helium-cooled beryllium-multiplying SiC composite blanket and shield for ARIES-I power reactor

\begin{tabular}{|c|c|c|}
\hline Zone & $\begin{array}{l}\text { Thickness } \\
(\mathrm{cm})\end{array}$ & Compositions \\
\hline $\begin{array}{l}\text { First Wall } \\
\text { Sacrificial layer } \\
\text { Structural wall }\end{array}$ & $\begin{array}{l}0.2 \\
1\end{array}$ & $\begin{array}{l}100 \% \mathrm{SiC} \\
67 \% \mathrm{SiC}+33 \% \mathrm{HE}\end{array}$ \\
\hline Breeding Zone & 20 & $\begin{array}{l}25 \% \mathrm{SiC}+70 \% \text { breeder } / \mathrm{Be}+5 \% \mathrm{He}(\text { breeder } / \mathrm{Be}-80 \% \mathrm{Be}+20 \% \text { breeder, } \\
\left.72 \% \text { density factor, principal breeder is } \mathrm{Li}_{2} \mathrm{ZrO}_{3}\right)\end{array}$ \\
\hline Reflector 1 & 10 & $25 \% \mathrm{SiC}+70 \% \mathrm{Be}+5 \%$ He (Be density factor is $72 \%$ ) \\
\hline Reflector 2 & $\begin{array}{l}37 \text { (outboard) } \\
7 \text { (inboard) }\end{array}$ & $\begin{array}{l}75 \% \mathrm{SiC}+20 \% \text { void }+5 \% \text { He } \\
75 \% \mathrm{SiC}+20 \% \text { void }+5 \% \text { He }\end{array}$ \\
\hline Plenum & 30 & $75 \% \mathrm{SiC}+25 \% \mathrm{He}$ \\
\hline Vacuum Vessel & 1 & Aluminum alloy \\
\hline Shield 1 & $\begin{array}{l}40 \text { (outboard) } \\
40 \text { (inboard) }\end{array}$ & $\begin{array}{l}66.5 \% \mathrm{SiC}+28.5 \% \mathrm{~B}_{4} \mathrm{C}+5 \% \mathrm{He} \\
56 \% \mathrm{SiC}+24 \% \mathrm{~B}_{4} \mathrm{C}+20 \% \mathrm{He}\end{array}$ \\
\hline Shield 2 & $\begin{array}{l}40 \text { (outboard) } \\
30 \text { (inboard) }\end{array}$ & $\begin{array}{l}66.5 \% \mathrm{SiC}+28.5 \% \mathrm{~B}_{4} \mathrm{C}+5 \% \mathrm{He} \\
66.5 \% \mathrm{SiC}+28.5 \% \mathrm{~B}_{4} \mathrm{C}+5 \% \mathrm{He}\end{array}$ \\
\hline
\end{tabular}




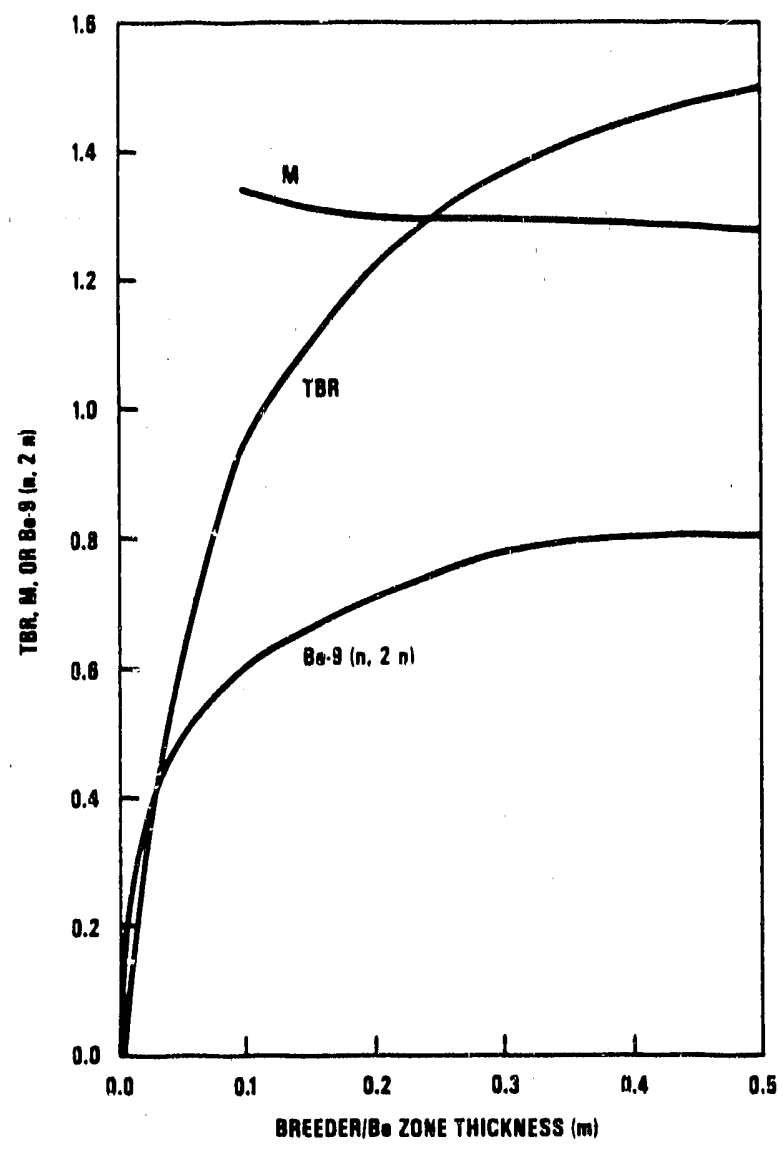

Fig. 1. Tritium breeding ratio (TBR), blanket energy multiplication (M), and $\mathrm{Be}(n, 2 n)$ as a function of breeder $\left(\mathrm{Li}_{2} \mathrm{ZrO}_{3}\right) /$ multiplier $(\mathrm{Be})$ zone thickness in ARIES-I reference blanket.

helium. The vacuum vessel, which is made of lowactivation aluminum alloy, is located outside of the gas plenum and is $10 \mathrm{~mm}$ thick. In the final design the vacuum vessel is located outside the shield and a stabilizing shell was added, composed of thin aluminum sheets dispersed throughout the shield. For the neutronics analysis, a thick shell in front of the shield was retained. Note that the total blanket thickness for the inboard location is $0.7 \mathrm{~m}$, while it is $1.0 \mathrm{~m}$ elsewhere.

The magnet shield is employed behind the blanket to protect the superconducting magnet. The most critical region of the magnet shield is located in the inboard as already well known for a tokamak reactor. For the ARIES-I reactor, the inboard shield is $0.7 \mathrm{~m}$ thick. The $0.3 \mathrm{~m}$ iegion nearest to the magnet employs a high density shield consisting of $95 \% \mathrm{SiC}$ and $\mathrm{B}_{4} \mathrm{C}$ shield and $5 \%$ helium. The $\mathrm{SiC}$ and $\mathrm{B}_{4} \mathrm{C}$ shield has the compositions of $70 \% \mathrm{SiC}$ and $30 \% \mathrm{~B}_{4} \mathrm{C}$. The $0.4 \mathrm{~m}$ of shield close to the vacuum vessel is, however, made

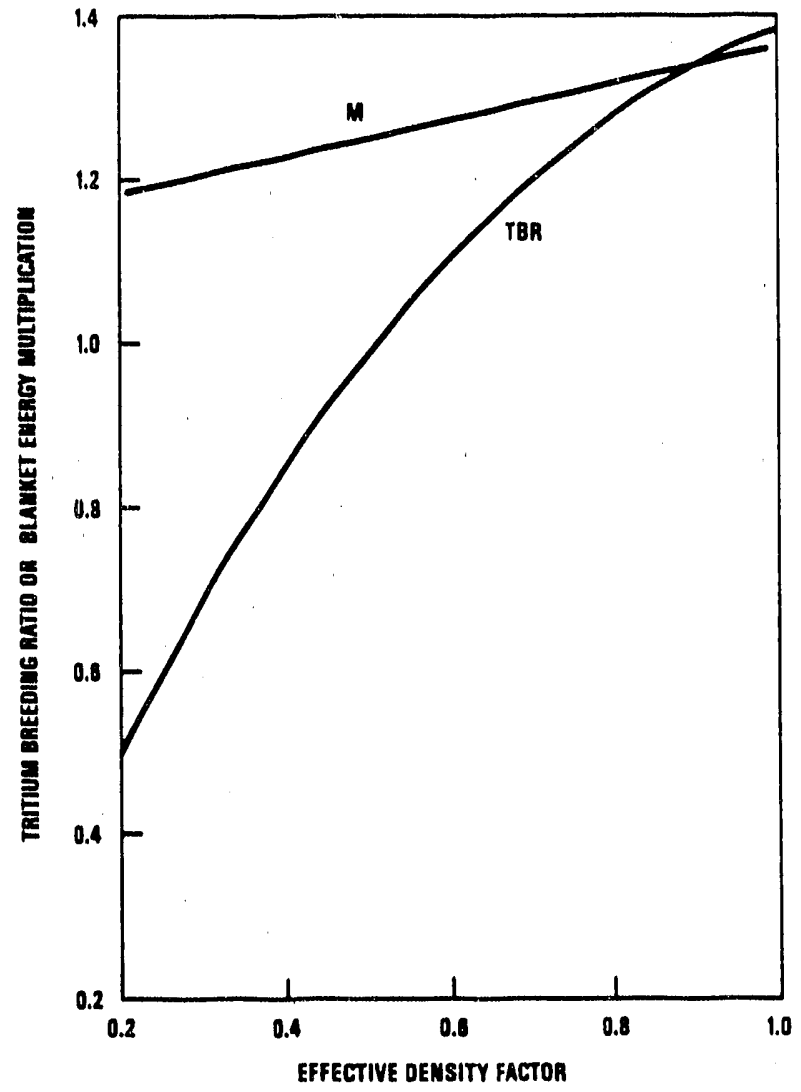

Fig. 2. Tritium breeding ratio (TBR) and blanket energy multiplication $(M)$ as a function of effective density factor of breeder $\left(\mathrm{Li}_{2} \mathrm{ZrO}_{3}\right) /$ multiplier (Be) partieles in ARIES-I blanket. The effective density factor is packing fraction times theoretical density.

of low-density shield particles. The packing fraction of these variable-size $\mathrm{SiC}$ and $\mathrm{B}_{4} \mathrm{C}$ particles is $80 \%$, allowing the particles to be extracted in order to create extra space behind the vacuum vessel when the vessel is to be disassembled. This shield zone is also cooled by low temperature helium. The shield elsewhere is designed to be $0.8 \mathrm{~m}$ thick and is made of high density shield materials.

The overall blanket and shicld thickness is $1.4 \mathrm{~m}$ for the inboard location, while it is $1.8 \mathrm{~m}$ elsewhere. The inboard blanket and sinield is capable of protecting the superconducting magnet against radiation damage through the entire life time of the ARIES-I power plant. In addition to the magnet protection, the $1.8 \mathrm{~m}$ blanket and shield elsewhere is also designed to reduce the activation level of reactor materials behind the blanket and shield component such that hands-on maintenance might be possible behind the shield. 


\section{ARIES-I BLANKET PERFORMANCE}

Table 2 displays the neutronic performance of the ARIES-I blanket and shield. Note that the Li-6 enrichment in the solid breeder $\mathrm{Li}_{2} \mathrm{ZrO}_{3}$ is $80 \%$ in lithium when the blaniret is fresh. At the end of blanket life, which is after $20 \mathrm{MW}-\mathrm{y} / \mathrm{m}^{2} 14 \mathrm{MeV}$ neutron exposure at the first wall, the lithium-6 drops to $25 \%$ of the initial enrichment, or $20 \%$. Figure 3 shows the TBR and $\mathrm{M}$ as a function of ${ }^{\circ} \mathrm{Li}$ enrichment in the breeder. As shown in Table 2 and Fig. 3, the tritium breeding ratio for ARIES-I from a 1-D full coverage analysis is 1.21 tritons per D-T neutron when the blanket is fresh. It reduces by $5.6 \%$, to 1.15 , at the end of blanket life. The average tritium breeding ratio over the blanket life is 1.18 , which is more than enough to guarantee an adequate tritium production in a realistic three-dimensional reactor geometry, including allowance for the installation of double-null divertor components, for sustaining the fusion fuel cycle in ARIES-I. This is so because in ARIES-I similar tritium breeding blankets will be installed behind the divertor components. The blanket energy multiplication is initially 1.30 , and then increases slightly to 1.32 at the end of blanket life, also shown in Table 2 and Fig. 3.

Figure 4 depicts the distribution of volumetric nuclear heating rates in the ARIES-I blanket components. Note that this figure is for the demonstration of nuclear heating rate in the breeding zone only, since the breeding zone and reflector thicknesses shown here are not that for the final design. As shown in Fig. 4, the maximum volumetric nuclear heating occurs at the breeder zone in the beryllium and breeder mixture

Table 2. Neutronic performance of the ARIES-I blanket and shield

\begin{tabular}{|c|c|c|}
\hline & $\begin{array}{c}\text { Beginning of Life } \\
\left(0 \mathrm{MW}-\mathrm{y} / \mathrm{m}^{2}\right) \\
(80 \% \mathrm{Li}-6)\end{array}$ & $\begin{array}{c}\text { End of Life } \\
\left(20 \mathrm{MW}-\mathrm{y} / \mathrm{m}^{2}\right) \\
(20 \% \mathrm{Li}-6)\end{array}$ \\
\hline 1. Tritium Breeding ( $T / D-T$ Neutro & & \\
\hline $\operatorname{Li}-6(n, \alpha) T$ & 1.1994 & 1.1337 \\
\hline $\operatorname{li}-7\left(n, n^{\prime} \alpha\right) T$ & 0.0036 & 0.036 \\
\hline$B e(n, T)$ & 0.0112 & 0.0114 \\
\hline 2. Neutron Multiplication (Reaction & & \\
\hline $\operatorname{Be}(n, 2 n)$ & 0.7516 & 0.7643 \\
\hline 3. Nuclear Heating (MeV/D-T Neut & & \\
\hline First wall & 0.8375 & 0.8449 \\
\hline Breeder zone & 13.35 & 13.06 \\
\hline Be reflector & 1.317 & 1.413 \\
\hline SiC reflector & 2.284 & 2.651 \\
\hline Plenum & 0.5495 & 0.6345 \\
\hline Total blanket heating & 18.34 & 18.60 \\
\hline Blanket energy multiplication, $M$ & 1.30 & 1.32 \\
\hline 4. Maximum Volumetric Nuclear He & & \\
\hline SiC first wall & $6.7^{(a)}$ & \\
\hline Breeder/Be mixture average & $11.0^{(a)}$ & \\
\hline \multicolumn{3}{|l|}{ 5. Nuclear Heating and Radiation } \\
\hline \multicolumn{3}{|l|}{ Damage at S/C Magnet } \\
\hline $\begin{array}{l}\text { Maximum nuclear heating } \\
\text { (inboard) }\end{array}$ & $370 \mathrm{~W} / \mathrm{m}^{3}(\mathrm{a})$ & \\
\hline Maximum fast neutron flux & $2.3 \times 10^{9} \mathrm{n} / \mathrm{cm}^{2} / \mathrm{s}^{(a)}$ & \\
\hline
\end{tabular}

(a) At $1 \mathrm{MW} / \mathrm{m}^{2}$. 


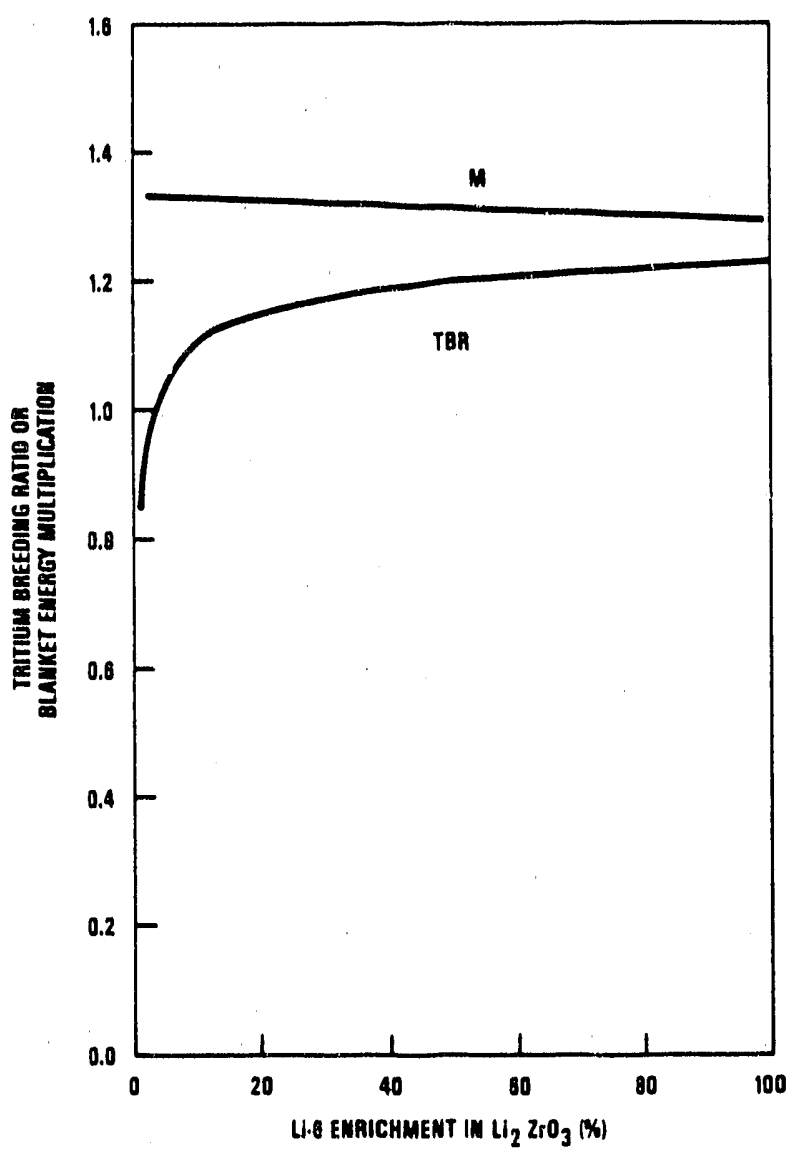

Fig. 3. Tritium breeding ratio (TBR) and blanket energy multiplication $(M)$, as a function of ${ }^{\circ} \mathrm{Li}$ enricinment in $\mathrm{Li}_{2} \mathrm{ZrO}_{3}$ breeder in the ARIES-I blanket.

immediately behind the SiC first wall, and is $11 \mathrm{~W} /$ cc for the mixture when normalized to $1 \mathrm{MW} / \mathrm{m}^{2}$ neutron wall loading. Otherwise, the volumetric nuclear heating in the breeder $\mathrm{Li}_{2} \mathrm{ZrO}_{3}$ alone will be close to $30 \mathrm{~W} / \mathrm{cc}$, as shown in Fig. 4. The volumetric nuclear heating at the $\mathrm{SiC}$ first wall, however, is only $6.7 \mathrm{~W} / \mathrm{cc}$ at $1 \mathrm{MW} / \mathrm{m}^{2}$.

The maximum nuclear heating at the superconducting magnet is located at the inboard region. It is about $370 \mathrm{~W} / \mathrm{m}^{3}$ at $1 \mathrm{MW} / \mathrm{m}^{2}$ neutron wall loading. The fast neutron (energy above $0.1 \mathrm{MeV}$ ) flux at the inboard super-conducting magnet is $2.3 \times 10^{9} \mathrm{n} / \mathrm{cm}^{2} / \mathrm{s}$ at $1 \mathrm{MW} / \mathrm{m}^{2}$. The superconducting magnet is more than capable of operating continuously for 40 years, since the radiation damage limit is believed to be $1.0 \times 10^{19} \mathrm{n} / \mathrm{cm}^{2}$ fast neutron fluence and the neutron wall loading at the inboard region is $2.4 \mathrm{MW} / \mathrm{m}^{2}$.

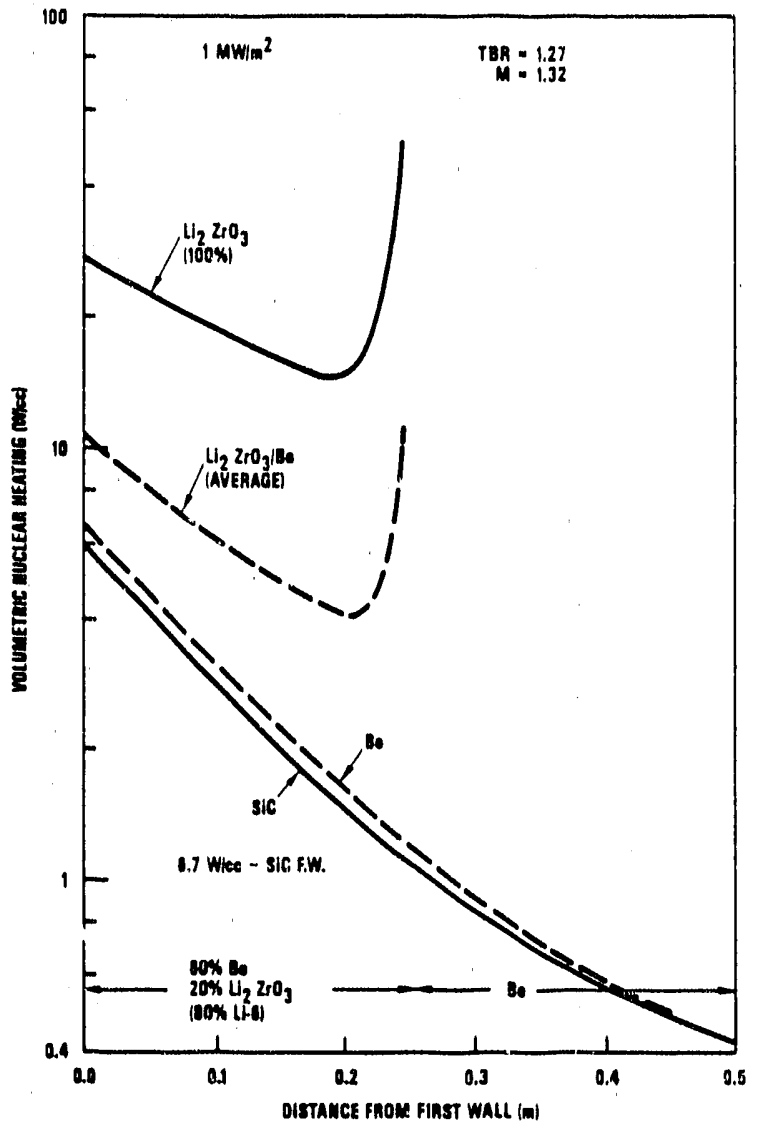

Fig. 4. Spatial distribution of volumetric nuclear heating rates in ARIES-I blanket components (normalized to $1 \mathrm{MW} / \mathrm{m}^{2}$ neutron wall loading).

\section{SUMMARY AND CONCLUSIONS}

A SiC composite blanket concept was recently conceived for a D-T burning, $1000 \mathrm{MW}(\mathrm{e})$ tokamak reactor design, ARIES-I, due to the low activation features of SiC material. High blanket nuclear perforinance, defined as maximum energy multiplication with adequate tritium breeding, is one of the design requirements for the ARIES reactor. Another major design requirement is to achieve a low level of activation. The major approach, other than using $\mathrm{SiC}$ as structural material, in meeting these design requirements is to employ beryllium, the only low activation neutron multiplying material, as a blanket material.

To maximize the blanket energy multiplication as well as to efficiently utilize the beryllium inventory, we 
have selected the blanket concept that employs a beryllium neutron multiplying zone immediately behind the first wall. $\mathrm{Li}_{4} \mathrm{SiO}_{4}, \mathrm{LiO}_{2}$, and $\mathrm{Li}_{2} \mathrm{ZrO}_{3}$ were among the solid breeder candidate materials considered for ARIES-I. Isotopically tailored $\mathrm{Li}_{2} \mathrm{ZrO}_{3}$ was selected as the reference breeder due to the high temperature stability requirement in the ARIES-I blanket environment, although $\mathrm{Li}_{4} \mathrm{SiO}_{4}$ and $\mathrm{Li}_{2} \mathrm{O}$ have demonstrated better low activation features. The tritium breeder, $\mathrm{Li}_{2} \mathrm{ZrO}_{3}$, is uniformly mixed with berillium to average out the operaiing power density in the breeder such that the maximum operating temperature would not exceed the design limit. High lithium-6 enrichment, up to $80 \%$ in lithium, will be needed due to high burnup in the blanket. To enhance the nuclear energy multiplication in the blanket, which is 1.3 in ARIES-I, we allow the excess neutrons to be absorbed in silicon $(Q=8.5 \mathrm{MeV})$ which appears as either structural or reflector material, $\mathrm{SiC}$.

The tritium breeding ratio for ARIES-I, from a 1-D full coverage analysis is 1.21 tritons per $\mathrm{D}-\mathrm{T}$ neutron when the blanket is fresh and it drops by $5.6 \%$, to 1.15 , at the end of blanket life which is taken as $20 \mathrm{MW}-\mathrm{y} / \mathrm{m}^{2}$ first wall exposure. The average tritium breeding ratio is 1.18 , which is more than enough to guarantee adequate tritium production in a realistic three-dimensional reactor geometry, including allowance for the installation of divertor components, for sustaining the fusion fuel cycle in ARIES-I.

\section{ACKNOWLEDGEMENT}

This work was supported by the U.S. Department of Energy under Contract No. DE-AC03-89ER52153.

\section{REFERENCES}

1. F. NAJMABADI, et al., "The ARIES Tokamak Reactor Study," Thirteenth Symposium of Fusion Engineering, Knoxville, Tennessee, October 1989.

2. C.P.C. WONG, et al., "Blanket Design for the ARIES-I Tokamak Reactor," ibid.

3. E.T. CHENG and the ARIES DESIGN TEAM, "Neutronics Studies for the ARIES-I Reactor," ibid, and references cited in this paper.

4. C.P.C. WONG, et al., "ARIES-I SiC Composite Low Activation Blanket Design," this conference.

5. J.S. HERRING, et al., "Activation Product Safety in the ARIES-I Reactor Design," this conference. 

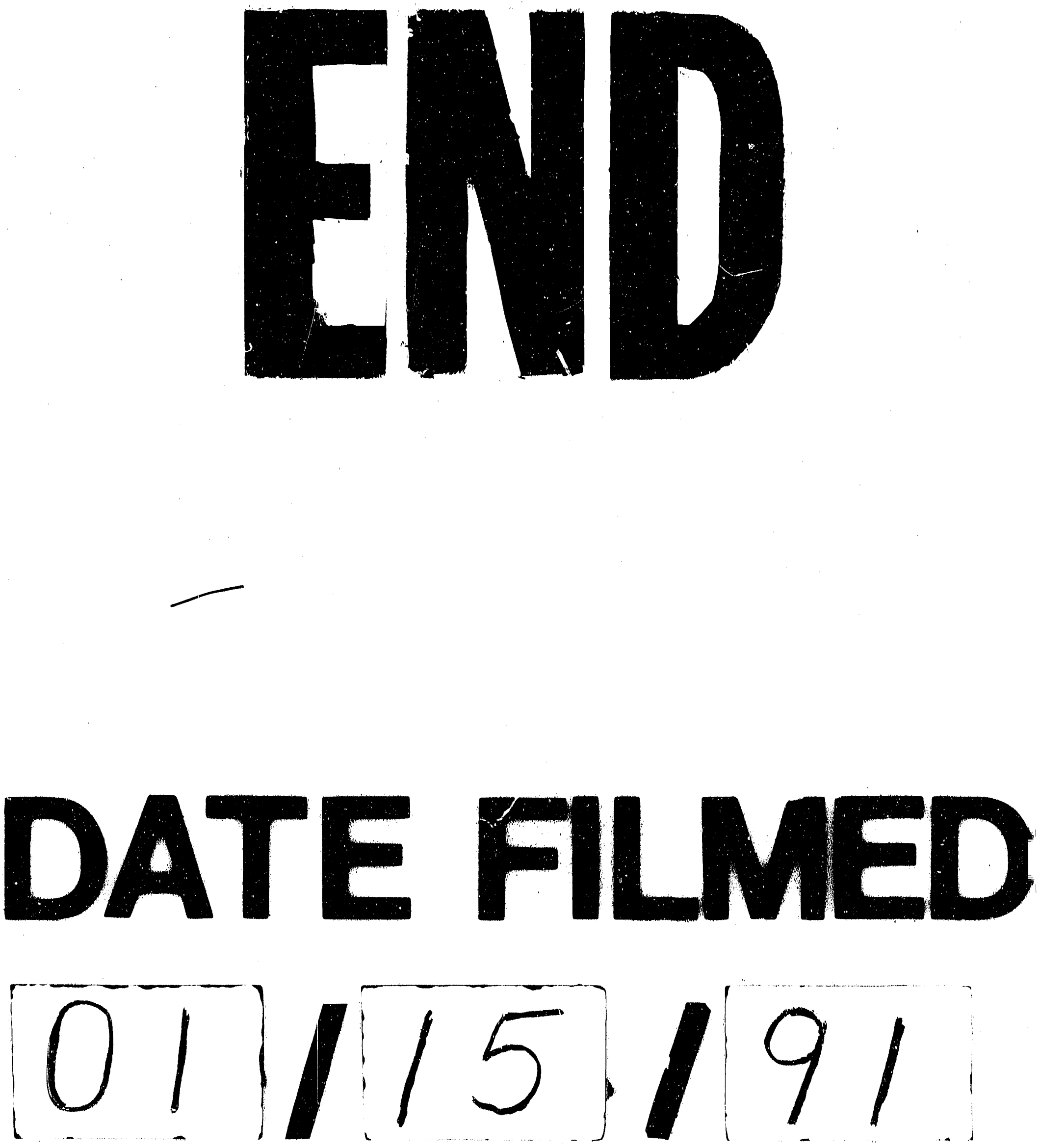
